the instrument is used with equal facility with either hand, and made to cut in either direction. The point being blunt, as also the edges down to three millimetres.from the tip, no damage to the cornea or the iris occurs.

I have operated on more than 15 cases and the instrument has served my purpose extremely well.

\title{
ANNOTATION
}

\section{Vision in Industry}

The National Ophthalmic Treatment Board (Industrial Section) has recently issued a leaflet (No. 37) in which the attention of employers is called to the fact that "efficient sight in many industries is probably the most important single factor contributing to high output, good work, diminished casualties, and the well-being and contentment of the workers."

Popular prejudice against spectacles and the idea that those who wear glasses have weak eyes and are therefore inferior to those who do not, has up to the present time militated against the general use of glasses in industry. This leaflet instances under four headings some of the workers for whom glasses are not only useful, but in some cases essential. Many occupations demand fine precision work and abnormally close scrutiny, such as linking in the hosiery trade, filament sorting in the electric industry and "drawing-in" in weaving. Some branches of the "fabric and printing industries demand accurate colour perception," for which a colour-blind person is obviously ill-suited; and no one questions the fact that motor drivers must possess an unrestricted field and good judgment of depth and distance. Again illumination is of the greatest importance in industrial concerns.

"To meet the requirements of industry the Board, with the approval of the British Medical Association, has prepared a scheme for the expert examination of the eyes of workers. Centres throughout the country with approved medical personnel and also for the supply of glasses by approved opticians have been arranged, and a reasonable scale of inclusive charges has been adopted.

"Many employers will no doubt wish to test for themselves the effect of this service upon their output and work upon a limited number of 'controls' before adopting it generally, and the Board will gladly provide the necessary facilities and technical advice." The advantages of such a scheme are self evident, and we hope that employers generally throughout the country will avail themselves of this offer. 